\title{
How to Minimize the Impact Caused by Global Pandemic in Malaysia
}

\author{
SMH Kabirl, Ahasanul Haque ${ }^{2}$, Mohammad Moshiur Rahman ${ }^{3}$ and Zainatul Shuhaida Abd \\ Rahman $^{4}$ \\ ${ }^{1,2,3}$ Department of Business Administration, International Islamic University Malaysia, \\ Kuala Lumpur, Malaysia \\ ${ }^{4}$ School of Multimedia Technology and Communication, Universiti Utara Malaysia,
} Kedah, Malaysia

\begin{abstract}
Infectious diseases like influenza, malaria are proved to be hazardous for humankind. While some became epidemic to a few geographical regions, the new Coronavirus (Covid-19) outbreak in almost every regions of the world made it a pandemic. Although clinical research and development evolved in today's modern age, a successful and recognized treatment over the disease has not been found yet. The global pandemic is probing countless impact on public health, the global economy, social and religious wellbeing. Previous researchers have undoubtedly emphasized the necessity and utter significance of pandemic preparedness at the global level. Still, very few have focused on the impacts of a global pandemic in Malaysia. The suggestions from the findings of this study will contribute to developing new knowledge in the functional domains of contingency during a pandemic crisis. The results will also help in developing governmental policy decisions for public health, economic development, social welfare and religious actions. Stringent measures during pandemic preparedness are discussed at the end of this paper.
\end{abstract}

Key words: Health, Economy, Social, Religious, Global Pandemic, Malaysia

\section{INTRODUCTION}

On 11th March 2020, Novel Coronavirus (2019$\mathrm{nCoV}$ ) has been declared as a pandemic by the World Health Organization [1]. Globally 2,719,897 confirmed cases and 187,705 deaths are being reported as of 25th April 2020 (2:00 am CEST) among which 5,742 confirmed cases and 98 deaths are being reported in Malaysia [2]. The unpredictable Coronavirus pushed the global health situation to an emergency that severely affected the global economy and social wellbeing of humankind. According to the International Monetary Fund (IMF), the Coronavirus pandemic will cause a global recession in 2020 , which is to be more profound than that of 2008-2009 global financial crises [3].

\section{COVID-19 FACTS SHEET FOR MALAYSIA}

- On 31st December 2019, the WHO Country Office in China was being told about instances of pneumonia caused by unknown reason found in Wuhan City, Hubei Province of China.

- From 31st December 2019 to 3rd January 2020, a total of 44 patients with pneumonia caused by unknown reason were accounted to WHO by the national experts in China. During this revealed period, the causal reason was not identified.

- On 11th and 12th January 2020, WHO got additionally full data from the National Health Commission China that the episode is related to exposures in a single fish market in Wuhan City.

- The Chinese specialists found another kind of Coronavirus, which was detached on 7 th January 2020.

- The new SARS-CoV-2 infection, which causes the sickness COVID-19, first 
showed up on Malaysian territory on 25th January 2020.

\section{GLOBAL PANDEMIC}

Pandemic is an epidemic that is happening around the world, or over a vast region, crossing worldwide limits and usually influencing countless individuals [4]. The WHO utilizes the term 'pandemic' for diseases that affects numerous individuals in different nations and is spreading (plague) on at any two contingents. Flu and AMR are two known pandemic dangers with conceivably pulverizing impacts on economies, society, and general wellbeing [5]. A pandemic of flu or correspondingly transmissible diseases could contaminate billions, murder millions, and thump trillions of dollars of worldwide gross domestic product (GDP). Indeed, even a progressively contained pandemic could kill millions and cost tens or many billions of dollars [6]. These dangers incorporate the standard lifestyle, financial, and cultural costs that are borne by nations, districts, and even all countries on account of pandemics. New and robust control of illness episodes forestalls significant wellbeing and financial costs, whether the disease can spread universally and turn into a pandemic.

Malaysia is a federal constitutional kingdom, situated in South-East Asia (Figure 1). As a multicultural nation, Malaysia is home to Malays, Chinese, Indians, Ibans, Kadazans and other ethnic gatherings. In 2016, $0.4 \%$ of the populace was underneath the national poverty line, having diminished substantially from $8.6 \%$ in 1999 , even though there stay steady imbalances for indigenous individuals and the bottom $40 \%$. The Malaysian wellbeing framework conveys a far-reaching scope of administrations through open and private suppliers. Malaysia has perhaps the most reduced rate of catastrophic health consumption in middlepay nations. Malaysia expects to turn into a high-pay country by 2020 through Vision 2020 and usage of the Eleventh Malaysia Plan 2016-2020 [7]. This arrangement supposed to give the all-encompassing system to Malaysia's overall improvement.

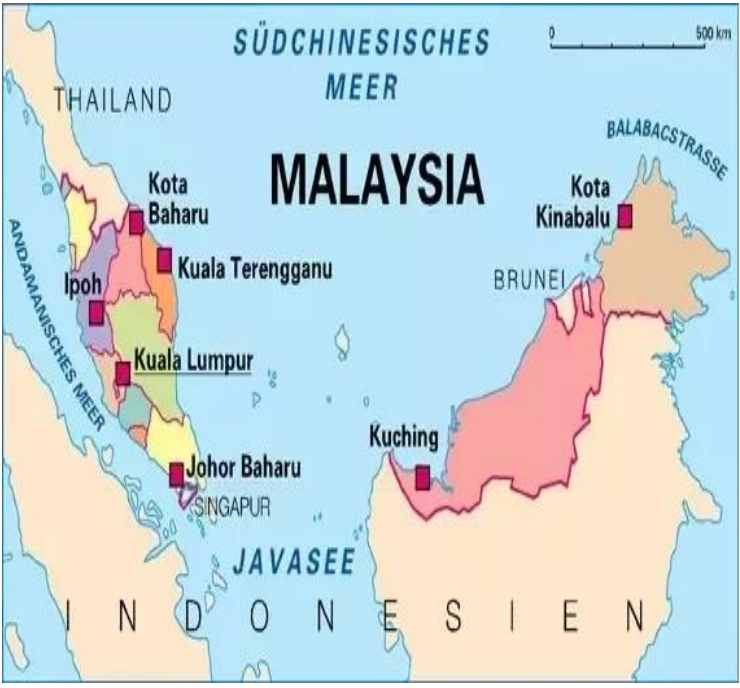

Figure 1. East and West Malaysia

\section{HEALTH IMPACT}

Full-bodied metrics for national-level preparedness are critical for assessing global resilience to pandemic outbreaks. Oppenheim et al. (2019) developed an Epidemic Preparedness Index (EPI) to assess country-level vigilance [8]. They covered 188 countries measuring each country's economic resources, public health communications, infrastructure, public health systems and institutional capacity. They evaluated the construct validity of the EPI and tested its correlation with proxy measures for preparedness and response capacity, including the timeliness of outbreak detection and reporting, as well as vaccination rates during the 2009 H1N1 influenza pandemic. They concluded that the most prepared countries were in Europe and North America, while the least prepared countries were in Central and West Africa and Southeast Asia. But, given the Covid-19 pandemic, their EPI measures were proved wrong as Europe and North America are found to be the most victimized.

In May 2018, the Global Preparedness Monitoring Board (GPMB) which is an independent monitoring and advocacy body collaborated with World Bank and WHO, urged government actions by all countries to prepare for and mitigate the effects of global health emergencies. In the wake of 20142016 Ebola epidemic, the United Nations SecretaryGeneral created Global Health Crises Task Force and Panel to work on preparedness for health emergencies and to focus in particular on biological risks manifesting as epidemics and pandemics (Kostova et al., 2019). The GPMB, in their first 
annual report (September 2019) mentioned seven most urgent needs and actions to accelerate for all countries that explore the challenges of preparedness through various dimensions: governance and coordination; country preparedness capacities; research and development; financing; enhancing community engagement and trust; preparing for and managing the fallout of a high-impact respiratory pathogen pandemics; and, lessons learned and persistent gaps revealed by recent outbreaks of Ebola virus disease in Africa [10]. For Malaysia, significant dengue epidemics, sustainable development goals in health issues and implications have been planned and partnered in the Country Cooperation Strategy (CCS) for the years 2016 to 2020 between Malaysia and WHO. But, unfortunately, there was no plan for facing pandemics and mitigation in the Malaysia health strategic priorities [11].

\section{ECONOMIC IMPACT}

The Covid-19 global pandemic is extreme compared to the Great Financial Crisis in 2007-08, as it hit family units, organizations, monetary foundations, and markets all simultaneously - first in China and now all around. What began as a progression of unexpected stops in monetary action, immediately fell through the economy and transformed into a complete shock at the same time obstructing market interest - as evident in the frail January-February readings of manufacturing and retail sectors. Industrial production growth in Malaysia was $0.6 \%$ in January 2020 before the Coronavirus outbreak impacted the economy (Figure 2). It was the weakest growth in industrial production since October 2019 mainly in textile, wearing, apparel, leather \& footwear, transport equipment \& other manufactures, non-metallic mineral products, basic metal \& fabricated metal products, electricity production and mining output - all edged down due to decreases in crude oil and natural gas. Again, the retail sales growth of Malaysia was $6.9 \%$ in December 2019 (Figure 3). It was the lowest growth since 2017. With a hit of the global pandemic, these ratings will go down further.

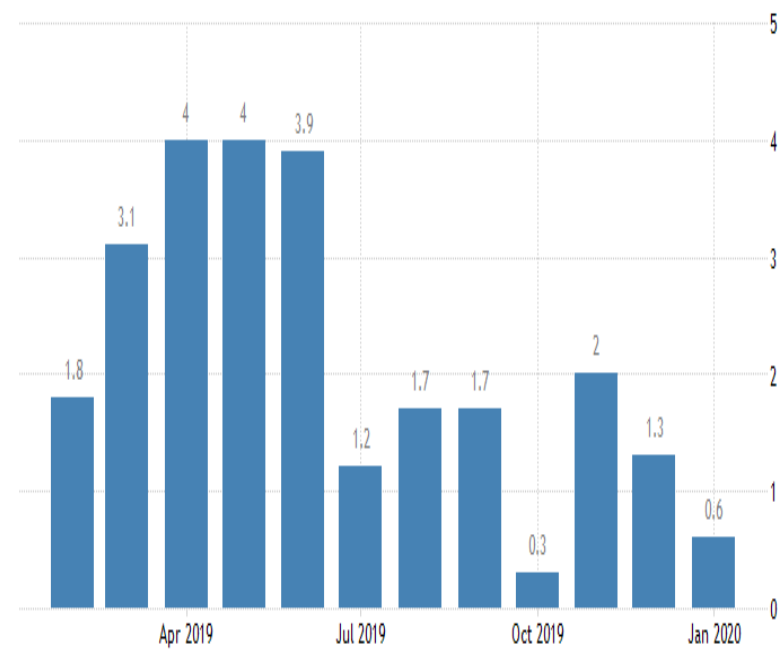

Figure 2. Industrial Output Growth in Malaysia from 2019 to 2020

Source: Department of Statistics Malaysia [12]

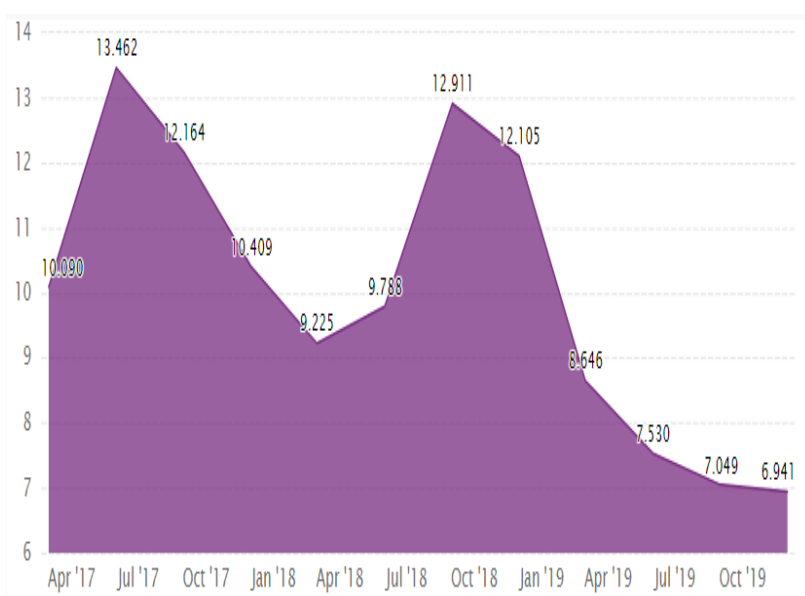

Figure 3. Retail Sales Growth in Malaysia from 2017 to 2019

Source: Department of Statistics Malaysia [13]

The global economy including capital markets impacted by Covid-19 profoundly. The intensity triggered more due to the recent fall of oil prices. From an economic point of view, lower oil prices are a positive indicator for most economies in the world. It implies lower import bills and acts like a tax cut for customers and businesses. But, Malaysia as an oil exporter dampens their demand, posing challenges to Asia's export performance and limiting their ability to introduce further fiscal stimulus. The global pandemic also hit the already weak property sector in Malaysia over the last couple of weeks. Sales and rental of properties may drop further by $5 \%$ to $10 \%$. Malaysian palm oil 
futures fell 5 per cent as concerns over demand deepened after WHO declared the Coronavirus a pandemic. The benchmark palm oil contract for February delivery on the Bursa Malaysia Derivatives Exchange slid 119 ringgits, or 5 per cent, to 2241 ringgit (\$527.29) during early trade [14]. Palm has already fallen more than 8 per cent as a sharp drop in crude oil prices and the rapid global spread of Covid-19. The tourism sector in Malaysia is being treated as having the most drastic hit, with flights, cruises, hotels and the web of businesses who feed off the industry struggling to run [15]. The hotel industry is already counting a financial loss of RM 70 million.

\section{SOCIAL IMPACT}

The COVID-19 pandemic is having an impact on the health of Malaysian people, the businesses Malaysia rely upon, and the way Malaysian live their daily lives. Various restrictions on economic activity through movement control order (MCO) reduced consumer spending as a lack of social security which plays a significant impact in crisis moments. The spread of Covid-19 outbreak has pushed disorder on daily life, grinding most of our routines and plans to a cut short. Educational institutions in Malaysia have cancelled classes and exams. All public events have been cancelled. Although these restrictions are a smart move for public safety, all these cancellations, particularly of major events, are taking a substantial financial loss.

The new Malaysian government announced various stimulus packages worth about 250 billion ringgits in 27th March 2019, which is an addition of 20 billion ringgit stimulus plan announced earlier. The stimulus package mostly includes onetime payments and discounts on utility bills for people whose occupation has been severely affected by the pandemic. It will also help the small and mediumsized businesses to keep on afloat and maintain their employees. Due to the outbreak, people from all areas have become adapted to wearing masks, stocking up on essentials, cancelling family and social gatherings, scrapping travel plans and working from home. Workplaces have found options in a new era where work from home is an increasing part of people's regular schedule once it will become effective. Universities are becoming prepared to keep educating online. Sketches of such habits will undergo long after the MCO at ease, acting as needed when required. Social security systems are taking necessary measures to cope with an ongoing demand for economic benefits and services.

\section{RELIGIOUS IMPACT}

The emergence of COVID-19 as a threat has stopped day to day activities in the local and international arena and reminding us of the strong effect of diseases on humanity. As with the previous epidemics, boundaries are no barrier to the COVID19 virus, and the biological processes of it affect nature [16]. However, sociologists agree that religion is an integral social institution which ensuring a major stabilizing force to play a crucial integrative function for the society [17]. Thus, religious people, therefore, cope with today's extraordinary disturbance to the daily practices of their religion for the tremendous consequences of society's overall wellbeing.

Malaysia has succumbed to the task of upholding human freedom in the fight against pandemics through its battle to control diseases related to a human rally. In the middle of a global pandemic, where social distancing is a vital weapon in the fight against its propagation, preventing large-scale crowds is threatening attitudes towards religious and other freedoms. As reported by various news agencies in Malaysia, more than one-third of the reported cases were related to a religious gathering that took place from February 27 to March 1, 2020 and attended by around 16,000 people in a mosque near Kuala Lumpur. It is also revealed that neighboring countries Singapore and Brunei have registered cases that could be traced back to the same meeting. However, up to 30,000 people attended a Hindu festival at Teluk Bahang beach in Penang just before that. When it applies to health and the environment, attention must be given to maintaining public health. At the same time, solidarity is required as Malaysia is happily multi-cultural, multi-racial, and multi-religious, and does not slip into other people's pit of blame-seeking.

Like many other countries, Malaysia also enforces social distances and lockdowns due to the Coronavirus pandemic; thus, many places of worship have been temporarily closed. In this period of instability, religious leaders turned to biblical scriptures and doctrine to find guidance and promote good practices for the community. However, many spiritual activities have moved in quarantine mood 
to observe social distancing. There is no question that this pandemic has had some effect on how and where religious people will perceive and worship. Prominent fellow religious leaders from Islam, Christianity and Judaism provided statements as guidance for potential practice. The "fatwas" given to the group in the Muslim community to re-analyses religious practices and provided insightful guidance on how to change religious activities or procedures to meet the COVID-19 response. Under this approach, some people believe that to go to the mosque or church in this challenging time is crucial for them. But, the practice of social distance and self-ritual prayer method suggested by the Malaysian government cannot be ignored.

\section{CONTINGENCY PLAN}

A contingency plan is the capacity of a framework to keep working regardless of harms, misfortunes or momentous occasions. Courses of action for operational progression are a vital worry of pandemic readiness. The business contingency is comparable; however, it might require halting activities altogether for the firm to endure. The information and limits created by governments, general wellbeing offices, reaction and recuperation associations, networks, organizations, and people to adequately foresee, react to and recoup from the effects of likely, up and coming or current fiascos, including plagues and pandemics. A readiness plan builds up courses of action ahead of time to empower convenient, successful and suitable reactions to occasions or to develop debacle circumstances that may undermine society or the earth. Readiness for the first and prompt reaction is called crisis readiness [18]. Following are some recommendations that can be pursued to minimize the impact caused by global pandemic.

1. To achieve economic growth, supporting SMEs who are the employer of $60 \%$ of workers of Malaysia is vital. Policymakers need to continuously explore ways to help the SMEs with adjustments to existing products and services based on business conditions. Entrepreneurs need to innovate new products and services as customer needs. Digital payments have become the single option for businesses of any size as cash transactions are becoming impossible in the current situation. If businesses venture into new ways of selling, then digital payments can be a more trusted way to accept payments safely and securely through Blockchain technology [19]. Therefore, introducing virtual currencies or more specifically crypto currencies with centralized monetary control can be a better option.

2. Allocating resources within and across the community where different levels of clusters exist which requires substantial public investment. These clusters can be differentiated based on physical infrastructure, education, purchasing power, environmental protection and health plan.

3. Setting up of methods for social insurance which will enable income source in old age. It will help to get financial security against permanent disability, transitory job loss, and inadequate earnings that provide financial protection for medical expenses.

4. Establishing and authorizing a situation for secure and comprehensive financial development. Making this condition incorporates money of local and universal security, authorization of agreements and property rights, a guideline of cross outskirt streams (products and enterprises, capital, people), and setting up the overall structure and direction of the monetary framework. A dangerous atmospheric deviation and the danger of severe pandemics present specific difficulties to long haul financial development [20]. The low likelihood, however, conceivably obliterating pandemics represents a common hazard, yet especially a risk to bring lower-income nations - that warrants incorporation on the macroeconomic approach plan.

5. Monitoring whether a broad range of stakeholders are acting to prevent outbreaks from becoming epidemics, whether their capacities to respond to epidemics are robust, and whether preparedness to respond to pandemics and limit the resulting economic and health damage is improving. To effectively control outbreaks and managing of 
pandemic preparedness, it is not enough to have public health capacities to detect and mitigate crisis moments. Also, strong leadership is required for effective communications and measures taken from all stakeholders and especially from the people of the country during pandemic [21].

6. Malaysia can follow the other Muslim clerics that emphasised regulations issued by governments by creating fatwas. In the Islamic perception, prominent Muslim scholar Shaykh Bin Abdullah Bin Bayyah, President of the United Arab Emirates Council for Fatwa and Member of the Forum for the Promotion of Peace in Muslim Societies, released a fatwa (Fatwa No. 11) calling on the group to heed government orders and guidelines to cooperate in the fight against the disease and avoid its spread [22]. However, within this approach, Pope Francis encouraged Christians worldwide to join in times of joint prayer, adding stay unified.

\section{CONCLUSION}

Global pandemic impacts on a country's socioeconomic system through several channels, along with the public health, industrial production, retail sales, equities, consumerism, and tourism sectors in large. At the same time, disruption in the global supply chain may also be impacted, while the interconnectedness of contemporary economic capability that a pandemic can also implicate a worldwide business network. But, beyond the impacts, there is a huge gap in mitigating the influences in local level due to broader scale pandemic outbreak. Preparedness indexes need to be formulated with practical data projections. Pandemics in a contemporary globalized world will require nothing much less than a strong publicprivate partnerships and accountability for ultimate sustainable health and socio-economic security. Religious leaders need to inspire and implement preventive measures with an inclusive approach which will reflect the unique and critical roles in influencing values, attitudes, behaviours, and actions to affect the development and wellbeing of Malaysian people.
The COVID-19 global pandemic calls for an urgent entire social solution to avoid the spread of the virus. As the pandemic continues to cause unimaginable illness and increasing death tolls, it is particularly needed to aware of the increased vulnerability of the community. The global COVID-19 Multi-Religious Faith-in-Action Movement encourages all societies around the world to join hands with states, UN organizations and relevant civil society [23]. Therefore, a strategic alliance is now required to enhance multi-religious cooperation and civic engagement in the fight against the pandemic of COVID-19.

\section{REFERENCES}

[1] World Health Organization (March 2020) situation reports on Coronavirus disease (COVID-2019).

[2] Ministry of Health (MOH) Malaysia (2020). Retrieve from

http://www.moh.gov.my/index.php/pages/view/201 9-ncov-wuhan.

[3] Kose, A., Sugawara, N. and Terrones, M. (2020). Global recessions. CEPR Working Paper, No. 14397.

[4] Tappero, J. W., Cassell, C. H., Bunnell, R., Angulo, F. J., Craig, A., Pesik, N. And Martin, R. (2017). US centers for disease control and prevention and its partners' contributions to global health security. Emerging Infectious Diseases, Vol. 23, No. 13, 10.3201/eid2313.170946.

[5] Leiva-Leon, D., Perez-Quiros, G. and Rots, E. (2020). Real-time weakness of the global economy: A first assessment of the Coronavirus crisis. ECB Working Paper No. 2381.

[6] National Research Council (2016). The neglected dimension of global security: A framework to counter infectious disease crises. Washington, DC: The National Academies Press, 10.17226/21891.

[7] Lee, C. and Lee, C. G. (2017). The Evolution of Development Planning in Malaysia. Journal of Southeast Asian Economies, 34, pp. 436-461, 10.1355/ae34-3b.

[8] Oppenheim, B., Gallivan, M. and Madhav, N. K. et al. (2019). Assessing global preparedness for the next pandemic: development and application of an Epidemic Preparedness Index. BMJ Glob Health, doi:10.1136/bmjgh2018- 001157. 
[9] Kostova, D., Cassell, C.H., Redd, J.T., Williams, D.E., Singh, T., Martel, L.D. and Bunnell, R.E. (2019). Long-distance effects of epidemics: Assessing the link between the 2014 West Africa Ebola outbreak and U.S. exports and employment. Health Economics, August.

[10] Global Preparedness Monitoring Board (2019). A world at risk: annual report on global preparedness for health emergencies. Geneva: World Health Organization, Licence: CC BYNC-SA 3.0 IGO.

[11] WHO/CCU/18.02/Malaysia (2018). World Health Organization - Country Cooperation Strategy for Malaysia. Updated May 2018.

[12] Department of Statistics Malaysia Official Portal. [online] https://www.dosm.gov.my.

[13] Ibid., ref. 12 above.

[14] Bursa Malaysia Berhad Official Portal. [online] https://www.bursamalaysia.com.

[15] Karim, M., Haque, A., Anis, Z., Ulfy, M. A. (2020). The Movement Control Order (MCO) for COVID-19 Crisis and its Impact on Tourism and Hospitality Sector in Malaysia. 3. 1-07. 10.37227/ithj-2020-02-09.

[16] Chinazzi, Matteo \& Davis, Jessica \& Ajelli, Marco \& Gioannini, Corrado \& Litvinova, Maria \& Merler, Stefano \& Piontti, Ana \& Mu, Kunpeng \& Rossi, Luca \& Sun, Kaiyuan \& Viboud, Cécile \& Xiong, Xinyue \& Yu, Hongjie \& Halloran, M. \& Longini, Ira \& Vespignani, Alessandro. (2020). The effect of travel restrictions on the spread of the 2019 novel coronavirus (COVID-19) outbreak. Science. 368. eaba9757. 10.1126/science.aba 9757.
[17] Hope, A. L.B. \& Jones, C. R. (2014). The impact of religious faith on attitudes to environmental issues and Carbon Capture and Storage (CCS) technologies: A mixed methods study. Technology in Society. 38 (2014) 4859.

[18] UNISDR Annual Report (2017). (2016-17) Biennium Work Programme Final Report'.

[19] Islam, M. R., Nor, R. M., Al-Shaikhli, I. F. and Mohammad, K. S. (2018). Cryptocurrency vs. Fiat Currency: Architecture, Algorithm, Cashflow \& Ledger Technology on Emerging Economy: The Influential Facts of Cryptocurrency and Fiat Currency. In: 2018 International Conference on Information and Communication Technology for the Muslim World (ICT4M), Kuala Lumpur, pp. 69-73.

[20] Fan, V. Y., Jamison, D. T. and Summers, L. H. (2018). Pandemic risk: how large are the expected losses?. Bulletin of the World Health Organization.

[21] Koonin, L. M. (2020). Novel coronavirus disease (COVID-19) outbreak: Now is the time to refresh pandemic plans. Journal of Business Continuity \& Emergency Planning Vol. 13, No. 4, pp. 1-15.

[22] UAE Council for Fatwa, Fatwa No. 11 (2020). Retrievfrom https://sandala.org/wpcontent/uploads/2020/0 3/Fatwa-11-COVID-19.pdf.

[23] UNICEF (2020). Retrieve from https://www.unicef.org/press-releases/launchglobal-multi-religious-faith-action-covid-19initiative. 